\title{
Redox changes across the Hangenberg Event (Devonian- Carboniferous boundary), Bakken Formation, North Dakota, USA
}

\author{
S.K. SAHOO ${ }^{1 *}$, A.J. KAUFMAN ${ }^{2}$, G.J. GILLEAUDEAU ${ }^{3}$,

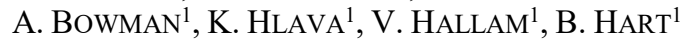 \\ ${ }^{1 *}$ Equinor US; swas@equinor.com; (*presenting author) \\ ${ }^{2}$ Geology and ESSIC, UMD, kaufman@umd.edu \\ ${ }^{3}$ AOES, George Mason University, ggilleau@gmu.edu
}

The globally recorded Hangenberg Event near the Devonian-Carboniferous boundary is known as the final pulse of one of the major Phanerozoic mass extinctions. Extensive reducing conditions are often implicated in the Hangenberg biotic crisis, but local vs. global controls on marine anoxia are often difficult to distinguish in the geologic record, especially during the Devonian Period when fundamental changes in plant evolution, weathering, and nutrient fluxes likely drove highly heterogeneous redox conditions across time and space. Many intracratonic basins in North America record extensive anoxia and deposition of organic-rich units, including the Bakken Formation in the Williston Basin. Although previous studies have addressed stratigraphic characteristics of the Bakken Shale, here we use a multiproxy geochemical dataset to parse the varying controls on black shale deposition, including basin hydrography and global ocean redox.

Data from multiple cores across the basin show that molybdenum (Mo) enrichments typical of modern euxinic (anoxic $+\mathrm{H}_{2} \mathrm{~S}$ ) environments are observed throughout the Lower Bakken Formation (LBF). In contrast, however, vanadium (V) is not substantially enriched above crustal levels until the upper part of the LBF. We are currently considering several hypotheses to explain the local vs. global nature of this enrichment pattern-however, a sharp shift towards lighter pyrite sulfur isotopes in one core points to a basin-wide flooding event that marks the onset of increased $\mathrm{V}$ enrichment. Correlation of a positive $\mathrm{N}$ isotope excursion to a similar feature that marks the Hangenberg Event in the Cleveland Shale (Appalachian Basin) gives us confidence that we can make some global redox interpretations for this important event. The strong Mo and V enrichments observed in open ocean euxinic shales of the upper LBF suggest a global ocean that was replete with Mo and V across the Hangenberg Event. These data argue against widespread global euxinia, which would act to draw down the seawater inventory of these metals. Future work is aimed at deciphering the complex environmental controls on black shale development during Late Devonian biotic crises. 